\title{
EFFECT OF SOLVENT DEGRADATION ON THE PUREX PROCESS
}

\section{by}

Thomas H. Siddall, III and Richard M. Wallace Separations Chemistry Division

Work done by

R. Mallace and W: $E$. Prout

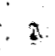
May 1958

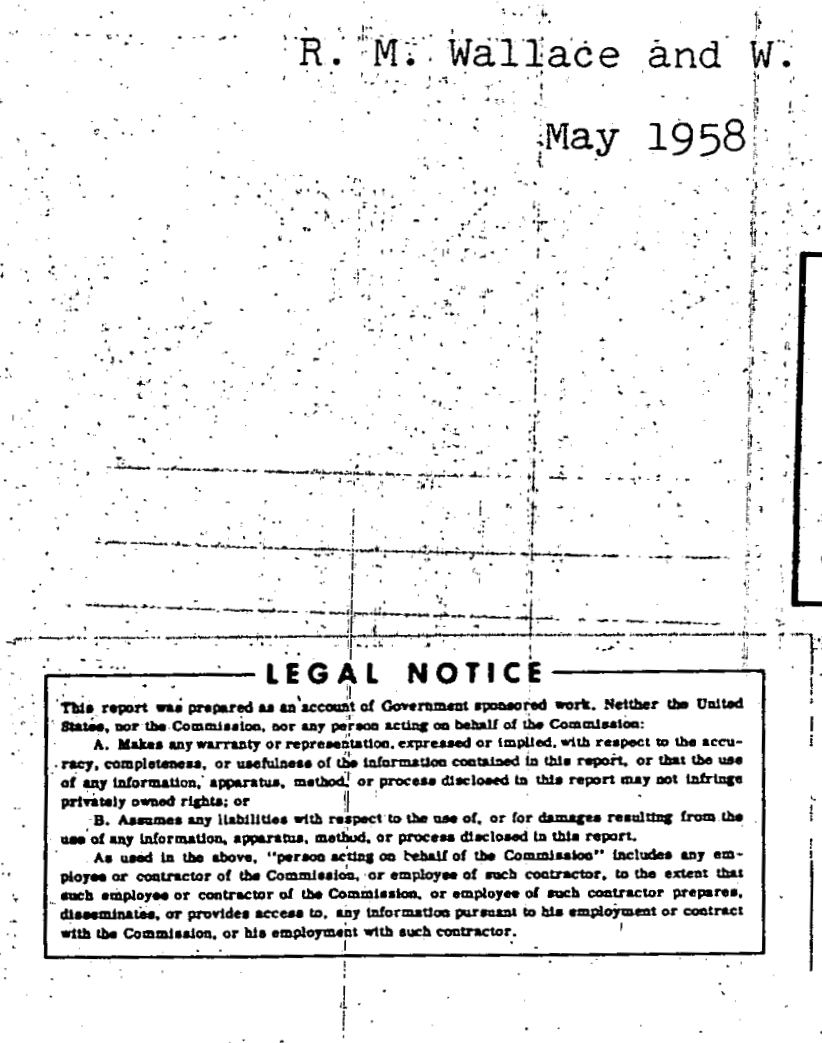

Photostat Price $\$ \quad 4.80$

Microfilm Price s 2.70

Available from the

Office of Technical Services

Department of Commerce

Washington 25, D.C.

E. I. du Pont de Nemours \& Co.

Explosives Department - Atomic Energy Division

Technical Division - Savannah River Laboratory

Printed for

The United States Atomic Energy Commission

(Contract AT(07-2)-1

Declassified with deletions March 18, 1960.

12001 


\section{DISCLAIMER}

This report was prepared as an account of work sponsored by an agency of the United States Government. Neither the United States Government nor any agency Thereof, nor any of their employees, makes any warranty, express or implied, or assumes any legal liability or responsibility for the accuracy, completeness, or usefulness of any information, apparatus, product, or process disclosed, or represents that its use would not infringe privately owned rights. Reference herein to any specific commercial product, process, or service by trade name, trademark, manufacturer, or otherwise does not necessarily constitute or imply its endorsement, recommendation, or favoring by the United States Government or any agency thereof. The views and opinions of authors expressed herein do not necessarily state or reflect those of the United States Government or any agency thereof. 


\section{DISCLAIMER}

Portions of this document may be illegible in electronic image products. Images are produced from the best available original document. 
The combined attack of $\mathrm{HNO}_{3}$ and $\mathrm{HNO}_{2}$ on the tributyl phosphate - kerosene solvent used in the Purex process produces degradation products that cause abnormal quantities of zirconium to be extracted along with the plutonium and uranium and thus limits the decontamination. 
CONTENTS

Page

LIST OF TABLES

INTRODUCTION . .

$\begin{array}{ll}\text { SUMMARY } & 5\end{array}$

$\begin{array}{ll}\text { DISCUSSION } & 5\end{array}$

The Solvent System in Use 5

Diagnosis of Plant Difficulties 6

Mechanism of the Effect of Degraded Solvent on
Decontamination

Development of the "Z" Test for Solvent quality 8

Reaction of Zirconium with Ligands 9

Alteration of Zirconium Ligands by Washing with Caustic 10

Rate of Ligand Formation in Acidic Systems 12

Discussion of Results 12

Experimental Work 13

Experimental Methods 16

Effect of DBP on the Extraction Coefficient of Zirconium 16

Solvent Degradation $\quad 16$

Determination of Zirconium Extraction Coefficients 16

Determination of Nitric Acid and Nitrous Acid 17

$\begin{array}{ll}\text { BIBLIOGRAPHY } & 17\end{array}$

$-3-$

$-3$ 


\section{LIST OF TABLES}

$\underline{\text { Table }}$

I Effect of Duration of Caustic Washes, 30-Second Acid Wash

II Effect of Duration of Acid Wash, 16-Hour Caustic Wash

III Degradation of 30\% TBP - "Ultrasene" in Absence of Nitrite at $40^{\circ} \mathrm{C}$

IV(A) Solvent Degradation at $40^{\circ} \mathrm{C}$ in Presence of $\mathrm{HNO}_{2}$ and $\mathrm{HNO}_{3}$; Constant $\mathrm{HNO}_{2}$, Varying. $\mathrm{HNO}_{3}$

IV(B) Solvent Degradation at $40^{\circ} \mathrm{C}$ in Presence of $\mathrm{HNO}_{2}$ and $\mathrm{HNO}_{3}$; Constant $\mathrm{HNO}_{3}$, Varying $\mathrm{HNO}_{2}$

V Summary of Degradation Results

VI Degradation of $30 \% \mathrm{TBP}$ - "Ultrasene" at $70^{\circ} \mathrm{C}$; No Added $\mathrm{HNO}_{2}$

VII Degradation of $30 \%$ TBP - "Ultrasene" at $70^{\circ} \mathrm{C}$ with Added $\mathrm{HNO}_{2}$ 


\section{EFFECT OF SOLVENT DEGRADATION ON \\ THE PUREX PROCESS}

\section{INTRODUCTION}

Operating experience with the Purex process showed that the solvent in the process was extensively degraded after only a few months of use. The washes given the solvent during each wash cycle effectively removed the di-n-butyl phosphate (DBP), but did not remove other degradation products. One symptom and serious effect of the presence of the other degradation products was the failure to achieve normal separation of the products from zirconium.

The first objective of the work covered in this report was to test the hypothesis that degraded solvent was responsible for poor separation of uranium and plutonium from zirconium. Further objectives were to learn how to control or minimize degradation and to establish the chemical basis of the effect on decontamination.

\section{SUMMARY}

Laboratory investigations demonstrated that poor zirconium separation was-due-to-degraded-solvent.

The combined attack of nitrous acid and nitric acid produces the degradation products which accumulate in solvent and interfere with zirconium separation. The formation of these products may be avoided or at least minimized where it is possible to avold the simultaneous presence of nitrous acid and of greater than 0.4 mol/liter of nitric acid in the solvent phase. At $70^{\circ} \mathrm{C}$, nitrous acid is formed in the system and therefore cannot be avolded if nitric acid is present. At $30^{\circ} \mathrm{C}$, nitrous acid is not formed at an appreciable rate.

The mechanism whereby degraded solvent adversely affects zirconium separation was demonstrated to a considerable degree. Two or more types of $z i r-$ conium ligands are formed in the solvent. Since the ligands are firmly held by the organic phase, they are not removed by washing in the solvent recovery step of the Purex process. These ligands are potent agents for extracting zirconium even when they are present to as small an extent as 100 parts per billion of solvent. once the zirconlum is extracted the reverse, or scrubbing, reaction is slow. These combined effects allow abnormal quantities of zirconium to be extracted with and remain with the products as they pass through the first contactor in the process. Some of the excess zirconium is slowly stripped with the products in the second and third contactors while a comparable amount remains with the spent solvent from the first cycle of solvent extraction. A later report will show that the zirconium ligands are formed from unstable components in the diluent.

A solvent quality test, called the " $Z$ " test, was devised on the basis of the behavior of these ligands in retaining zirconium. Tracer zirconium in $3 \mathrm{M}$ nitric acid is extracted into the solvent sample. The concentration of zirconium held by the solvent after it is scrubbed with $3 \mathrm{M}$ nitric acid is the measure of the extent of solvent degradation and is expressed as the " $Z$ " number. The units of the "l" number are $1 \times 10^{-9}$ mols/liter of solvent.

\section{$\underline{\text { DISCUSSION }}$}

THE SOLVENT SYSTEM IN USE

For the convenlence of the reader the solvent system in use in the Plant at the time of the laboratory work is described briefly. The solvent used in the irst cycle of solvent extraction and that used in the second plutonium cycle were combined in one system which was commonly called the "hot" solvent system or first cycle solvent system. The solvent used in the second uranium cycle was kept

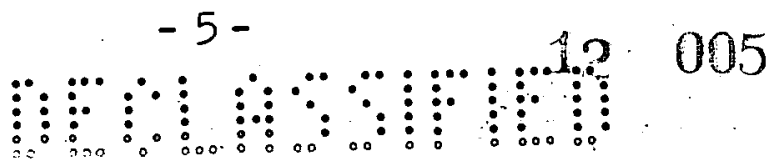


segregated in a separate system known as the "warm" system or second cycle system. The solvent from the "hot" system. caused most of the trouble and consequently has recelved most of the attention.

After each passage through the mixer-settiers, solvent was sent to the solvent recovery step. In the solvent recovery equipment the solvent was washed batchwise with a 0.1M solution of sodium hydroxide, with water and with very dilute nitric acid.

In addition to the solvent in the main Purex system, a batch of solvent was kept in a "rerun" station. This solvent was used in batch equilibrations to recover plutonium and uranium from aqueous wastes which occasionally contained excessive quantities of these elements. Rerun solvent was washed on only a few occasions at irregular intervals.

The solvent is 30 to $35 \%$ tri-n-butyl phosphate (TBP) by volume in "Ultrasene:" "Ultrasene" is a commercially available refined kerosene which is composed of a mixture of saturated paraffins.

The coded nomenclature for process streams is:

\begin{tabular}{ll} 
& Code \\
\hline Aqueous feed to first cycle & IAF \\
Solvent to la contactor (the first & \\
$\quad$ contactor in the cascade) & IAX \\
Scrub stream to 1A contactor & IAS \\
Solvent leaving IA contactor & IAP \\
Plutonium product stream from first cycle & IBP \\
Uranium product stream from first cycle & ICU \\
Spent solvent from first cycle & ICW
\end{tabular}

DIAGNOSIS OF PLANT DIFFICULTIES

The laboratory program proved that difficulties with zirconium were due mainly to solvent degraded in the rerun system. Solvent which had been in use for about three months in the main hot system was compared with virgin solvent by making miniature mixer-settler runs. The used solvent performed essentially as well as the virgin solvent. Any differences were too small to be significant.

During the next month, solvent from the rerun station was returned to the hot solvent system in the ratio of 2 parts of rerun solvent to 15 parts of. hot solvent. The solvent from the rerun station had been washed only a few times in several months of use and routinely was exposed to high concentrations of nitrous and nitric acids for long periods of time.

The introduction of this degraded solvent into the main process was followed by generally poorer decontamination of the product streams and an increase in the level of activity of the $1 \mathrm{CW}$ and washed solvent. The increased activity levels were due almost entirely to $\mathrm{Zr}-\mathrm{Nb}$. A few scattered analyses indicated that most of the $\mathrm{Zr}-\mathrm{Nb}$ was zirconium.

After the introduction of the rerun solvent, unused solvent and plant solvent were again compared in two miniature mixer-settler runs. This comparison showed that plant solvent possessed strikingly abnormal affinity for $\mathrm{Zr}-\mathrm{Nb}$.

The same batch of IAF was used in both runs; the plant solvent was a composite of samples of washed first cycle solvent. Solvent was given the standard plant recovery treatment immediately before use.

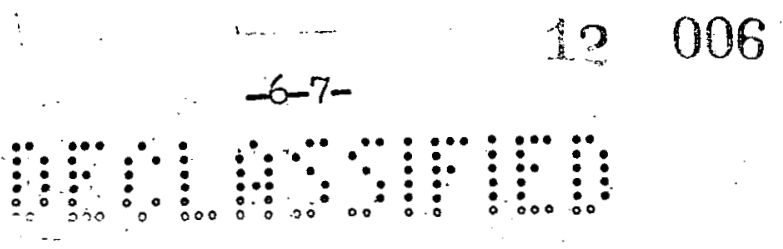




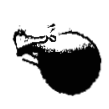

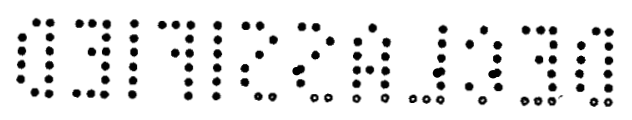


Plant solvent gave a poorer $\mathrm{Zr}-\mathrm{Nb}$ decontamination across the $1 \mathrm{~A}$ bank. Beta, gamma, and ruthenium decontamination were essentially the same with unused or plant solvent. The major portion of this $\mathrm{Zr}-\mathrm{Nb}$ was retained by the solvent and appeared in the $1 \mathrm{CW}$. Spent solvent from the run with plant hot solvent retained 27 times as much $\mathrm{Zr}-\mathrm{Nb}$ as virgin solvent.

The ruthenium decontamination was poor, but the same for both runs. The low temperature was probably responsible.

\section{MECHANISM OF THE EFFECT OF DEGRADED SOLVENT ON DECONTAMINATION}

\section{Development of the " $\mathrm{z}$ " Test for Solvent Quality.}

The experiment which follows showed that degradation products are present in used solvent which becomes saturated with zirconium. It showed that after the solvent was contacted with a solution of zirconium tracer, most of the zirconium held by TBP could be preferentially scrubbed away, leaving a residue which was tightly bound by impurities in the degraded plant solvent. The retained zirconium could be measured reproduclbiy. Over a wide range, the amount retained was independent of the concentration of zirconium used when contacting the solvent. The amount of: zirconium retained was taken as an index of solvent quality. The procedure is called the " $z$ " test and the amount of zirconium retained (in units of $1 \times 10^{-9}$ mols/liter of solvent) is called the "z" number.

$\therefore \quad \therefore$ The solvent used in this experiment was drawn from the first cycle of the Purex process. It was some of the same solvent mentioned in the description of the minfature mixer-settler runs in the previous section, except that it had been used for two more months. The solvent was washed briefly with a caustic solution and then equilibrated with 3 M nitric acid immediately before use. The caustic washing removed all the zirconium activity and much of the ruthenium from the solvent.

Various volumes of a solution containing $9.2 \times 10^{-3} \mathrm{mg} / \mathrm{ml}$ of stable $\mathrm{zir}-$ conium In $3 \mathrm{M}$ nitric acid were added to centrifuge cones containing two ml of zirconium-95 tracer $\left(6: 9 \times 10^{4}\right.$ beta $\left.\mathrm{c} / \mathrm{m}-\mathrm{ml}\right)$ in $3 \mathrm{jin}$ nitric acid. The solutions were mixed and then held at $50^{\circ} \mathrm{C}$ for one hour to allow the zirconium to exchange. The solutions were cooled and two ml of the used solvent were added to each cone. The phases were agitated at $23^{\circ} \mathrm{C}$ for one hour and the separated organic phases were scrubbed for one minute three times with equal volumes of $3 \mathrm{M}$ nitric acid. After scrubbing, the organic phases were counted for zirconium beta activity. Niobium and ruthenium were excluded by counting through aluminum absorbers.

If poor zirconium retention is caused by the saturation of specific degradation products with zirconium according to the mechanism proposed, the behavior of the system should be predictable as given below.

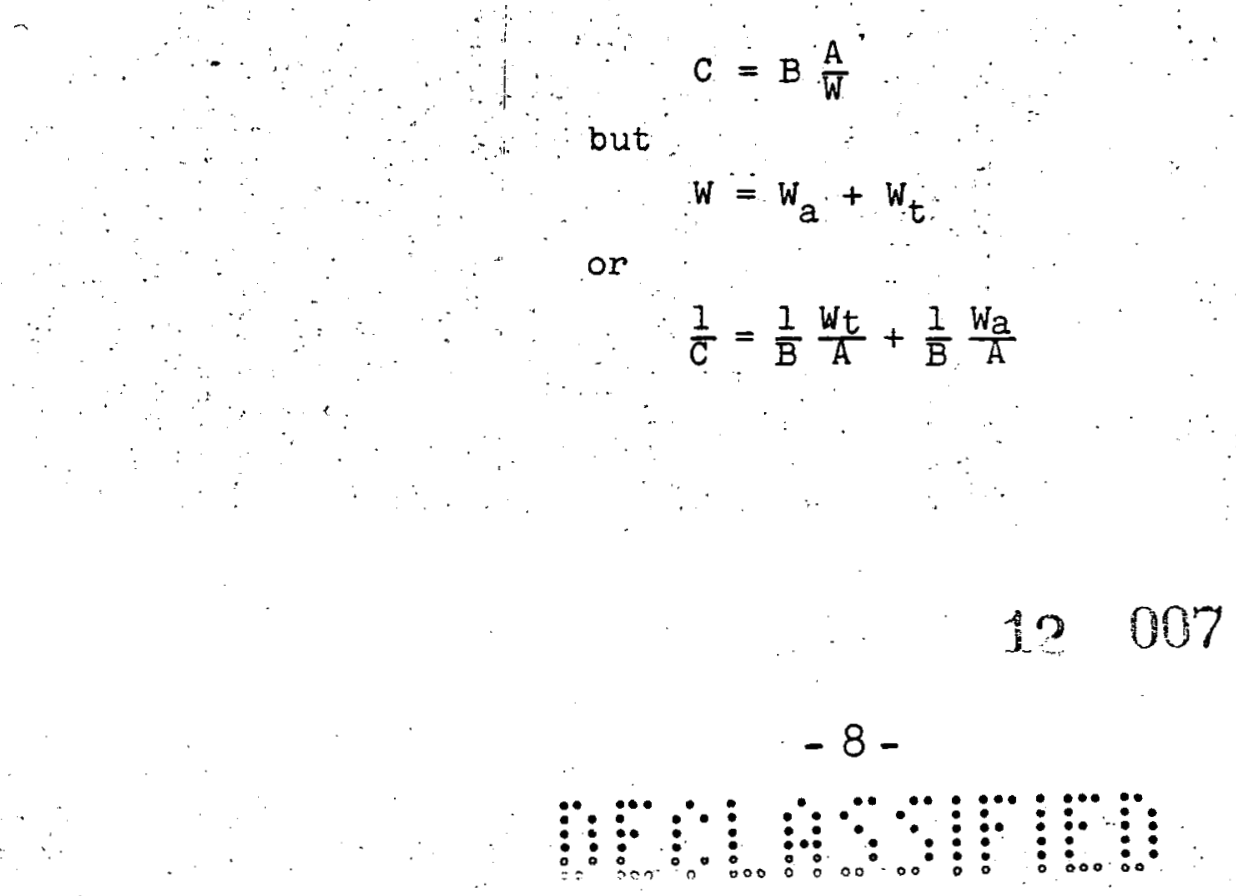


where

$B$ - concentration of zirconium held by the solvent after scrubbing

C - zirconium beta counts held per $\mathrm{ml}$ of scrubbed solvent

A - zirconium beta counts in two $\mathrm{ml}$ of the tracer

W - total milligrams of zirconium in the aqueous phase before adding solvent

$W_{t}$ - milligrams of zirconium which were in the two ml of tracer

$W_{a}$ - milligrams of stable zirconium added

Therefore, provided $B$ is truly a constant, a plot of $\frac{1}{C} \mathrm{Vs}$. $\frac{W a}{\mathrm{~A}}$ will give a straight line. The slope of this Ilne will be $\frac{1}{\bar{B}}$ and the intercept will be $\frac{1}{\bar{B}} \frac{W t}{A}$. Since $A$ is known, both $W_{t}$ and $B$ can be calculated.

The data given in the following table were fitted to such a linear equation by the method of least squares. The experimental values were weighted according to estimated error. The weight factors are given in the last column of the table.

\section{Experimental Data}

\begin{tabular}{|c|c|c|c|c|}
\hline $\mathrm{w}_{\mathrm{a}}$ & $\mathrm{w}_{\mathrm{a}} / \mathrm{A}$ & C & $1 / \mathrm{C}$ & Weight Factor \\
\hline $4.59 \times 10^{-3}$ & $3.33 \times 10^{-8}$ & 181 & $5.5 \times 10^{-3}$ & 1 \\
\hline $2.76 \times 10^{-3}$ & $2.00 \times 10^{-8}$ & 273 & $3.66 \times 10^{-3}$ & 1 \\
\hline $1.84 \times 10^{-3}$ & $1.33 \times 10^{-8}$ & 307 & $3.26 \times 10^{-3}$ & 2 \\
\hline $9.2 \times 10^{-4}$ & $6.7 \times 10^{-8}$ & 551 & $1.88 \times 10^{-3}$ & 5 \\
\hline $4.59 \times 10^{-4}$ & $3.33 \times 10^{-9}$ & 648 & $1.54 \times 10^{-3}$ & 8 \\
\hline $9.2 \times 10^{-5}$ & $6.7 \times 10^{-10}$ & 1080 & $9.3 \times 10^{-4}$ & 20 \\
\hline 0 & 0 & 1180 & $8.5 \times 10^{-4}$ & 35 \\
\hline
\end{tabular}

The data fit the equation

$$
\frac{I}{c}=8.67 \times 10^{-4}+1.53 \times 10^{5} \mathrm{~W}_{\mathrm{a}} / \mathrm{A}
$$

with an average deviation of $6.1 \%$

$$
\begin{gathered}
\text { or } B=6.5 \times 10^{-6} \mathrm{mg} / \mathrm{ml} \text { or } 71 \times 10^{-9} \mathrm{mols} / 1 \text { iter } \\
\text { and } w_{t}=7.8 \times 10^{-4} \mathrm{mg}
\end{gathered}
$$

or the concentration of zirconium in the tracer $=3.9 \times 10^{-4} \mathrm{mg} / \mathrm{ml}$.

The fit of the data to the linear equation is certainly as good as the experimental precision. Also, a chemical analysis showed the tracer to contain $4 \times 10^{-4} \mathrm{mg} / \mathrm{ml}$ of zirconium.

\section{REACTION OF ZIRCONIUM WITH LIGANDS}

The ligands require hours to reach equilibrium in their reactions with zirconium. This fact was explicitly demonstrated in the experiment described below.

The solvent used in this experiment was degraded in the laboratory at $40^{\circ} \mathrm{C}$ for five days while containing $0.6 \mathrm{M} \mathrm{HNO}_{3}$ and $0.02 \mathrm{M} \mathrm{HNO}_{2}$. After degradation

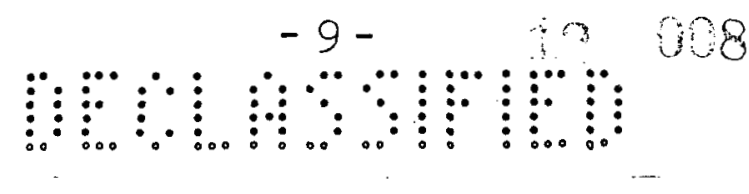


the solvent was washed for five minutes with an equal volume of IM caustic. After the caustic wash the solvent was mixed with $3 \mathrm{M}$ nitric acid and left standing for several days at $23^{\circ} \mathrm{C}$. Part of the solvent was then contacted with tracer and scrubbed several times with $3 \mathrm{M}^{-} \mathrm{HNO}_{3}$ until the activity in the organic phase contained only 800 beta $\mathrm{c} / \mathrm{m}-\mathrm{ml}$ of zirconium. At this point the sample was continuously agitated with $3 \mathrm{M} \mathrm{HNO}_{3}$ at $23^{\circ} \mathrm{C}$ with periodic sampling. The other part of the sample was then contacted for the first time with a dilution of the tracer stock which contained only 1500 beta $\mathrm{c} / \mathrm{m}-\mathrm{ml}$ of zirconium. In this fashion equilibrium could be approached from both directions. The data are given in the following table.

\section{Approach to Equilibrium}

\begin{tabular}{cc} 
Time & $\begin{array}{c}\text { Eirconium in Organic } \\
\text { Phase Initialiy }\end{array}$ \\
\cline { 2 - 2 } 1 minute & 7.6 \\
5 minutes & 6.4 \\
10 minutes & 4.9 \\
30 minutes & 3.4 \\
1 hour & 2.2 \\
2 hours & 1.9 \\
4 hours & 1.7 \\
16 hours & 1.3
\end{tabular}

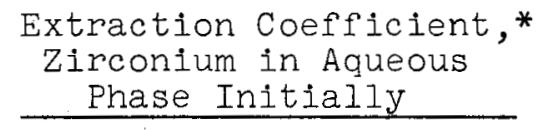

0.23

0.34

0.49

0.66

0.87

1.02

0.86

*Corrected for extraction due to TBP

ALTERATION OF ZIRCONIUM LIGANDS BY WASHING WITH CAUSTIC

The experiments described in this section demonstrated that there is more than one type of zirconium ligand in solvent degraded in the laboratory. When solvent is washed with caustic there is evidence of a new ligand which must be formed by the caustic, but is not removed by the caustic. This evidence is that the " $Z$ " number and also the extraction coefficients for zirconium increase with the duration of the caustic wash. The effects of a long caustic wash can be reversed in some degree by long acid pre-equilibrations before introducing the tracer or long equilibrations with the tracer in 3M nitric acid. Also, when degraded solvent which has had a lorg caustic wash is equilibrated with zirconium in $3 \mathrm{M}$ nitric acid, the ratio of ligand to zirconium in the complex slowly

decreases with time from $2: 1$ toward $1: 1$.

This behavior is suggestive of a keto-enol equilibrium. With such an hypothesis the keto species would form during the degradation. During the caustic wash the less effective keto species would convert to the enol species which are more effective as ligands for zirconium.

The first experiment (summarized in the following table) showed that the sample with the longer caustic wash and the shorter acid pre-equilibration gave the highest " $Z$ " number. The contact with tracer zirconium lasted for 30 minutes and the scrubs lasted for one minute each. The general procedure in determining "z" numbers in future experiments, except where noted, is an equal volume equilibration with tracer in $3 \mathrm{M}$ nitric acid for 30 minutes followed by three equalvolume scrubs for one minute with $3 \mathrm{M}$ nitric acid. The solvent for this experiment was degraded for five days at $40^{\circ} \mathrm{C}$ with $0.7 \mathrm{M} \mathrm{HNO}_{3}$ and $0.1 \mathrm{M} \mathrm{HNO}_{2}$ in the organic phase.

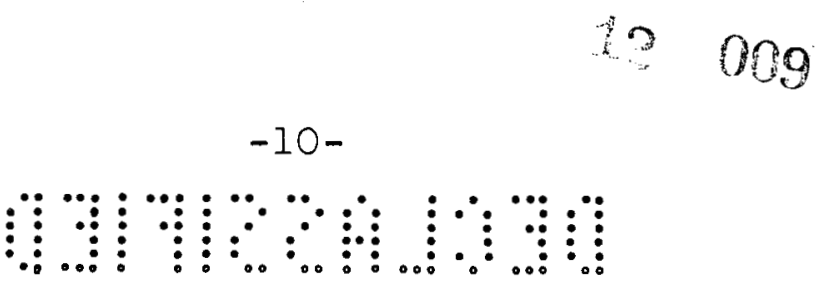


Effect of Caustic and Acid Washes

Duration of $\mathrm{NaOH}$ Wash, minutes

1

1

60

60
Duration of $\mathrm{HNO}_{3}$

Pre-equilibration

1

60

1

60
"Z" Number

570

530

800

610

The second experiment (Tables I and II) confirms the trend to higher "Z" numbers with longer caustic washes. It also shows that the effect of a very long caustic wash can be almost completely reversed with a long acid pre-equilibration.

The third experiment showed that solvent degraded at $70^{\circ} \mathrm{C}$ rather than at $40^{\circ} \mathrm{C}$ exhibited the same phenomenon of increased zirconium extraction with increased duration of caustic washing. The stoichiometry of the extraction reaction changed as the caustic-washed solvent was agitated with the tracer in $3 \mathrm{M}$ nitric acid. At the beginning of the agitation period two molecules of ligand combined per zirconium atom. After 72 hours the ratio decreased to 1.3 . This result indicated that a one-to-one complex was predominating.

The effect of the length of the caustic wash was examined first. The solvent, containing $0.9 \mathrm{M} \mathrm{HNO}_{3}$ and $0.04 \mathrm{M} \mathrm{HNO}_{2}$ was held at $70^{\circ} \mathrm{C}$ for 16 hours. $\mathrm{After}$ the washing with caustic the samples were quickly pre-equilibrated with $3 \mathrm{M}^{\mathrm{H}} \mathrm{HO}_{3}$ and then equilibrated with tracer at $23^{\circ} \mathrm{C}$ for 20 hours.

\section{Effect of Length of Caustic Wash}

Duration of $1 \mathrm{M} \mathrm{NaOH}$
Wash, hours

1

2

4

7

48
Extraction Coefficient for Zr, EO/A

13.8

19.2

31.4

32.7

48.8

The extraction coefficient of the $\mathrm{Zr}$ for the equilibration is quoted rather than the " $Z$ " number. With solvent degraded to such an extent all or nearly all the zirconium from the tracer would be recovered in all cases since the zirconlum concentration is too small to saturate the ligands.

Some of the same solvent was agitated with caustic for several days. Part of the solvent was diluted, one volume with four volumes of virgin solvent. After a brief pre-equilibration with $3 \mathrm{M} \mathrm{HNO}_{3}$, the degraded solvent and the dilution were agitated with tracer in $3 \mathrm{M} \mathrm{HNO}_{3}$ at $23^{\circ} \mathrm{C}$. Samples were taken at intervals and the extraction coefficients were determined for zirconium. The column labeled "S" represents the slopes of lines drawn between two points when the extraction coefficient is plotted against dilution on log-log paper.

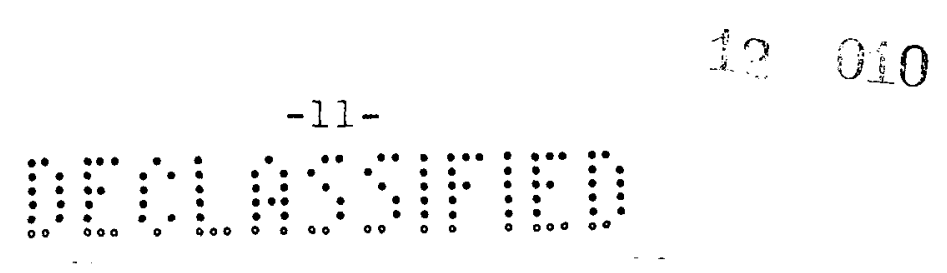


Stoichiometry of Ligands with Zirconium

\begin{tabular}{ccccc}
$\begin{array}{c}\text { Contact Time, } \\
\text { hours }\end{array}$ & $\begin{array}{c}\text { Extraction } \\
\text { Coefficient, 100\% }\end{array}$ & $\begin{array}{c}\text { Extraction } \\
\text { Coefficient, 20\% }\end{array}$ & S \\
\cline { 2 - 5 } 1 & 104 & 3.9 & 1.97 \\
2 & 216 & 11.0 & 1.75 \\
3 & 115 & 9.9 & 1.58 \\
16 & 61 & 6.9 & 1.40 \\
48 & 44 & 4.9 & 1.34 \\
72 & 31 & 3.7 & 1.31
\end{tabular}

RATE OF LIGAND FORMATION IN ACIDIC SYSTEMS

Discussion of Results

The evidence for more than one type of ligand following caustic washing of degraded solvent was sufficient to discourage quantitative study of the rate of zirconium ligand formation under these conditions. Dibutyl phosphate (DBP) forms from TBP while the solvent is being degraded. Without a caustic wash DBP will remain with the solvent and will extract zirconium. The extraction of zirconium by DBP complicates the interpretation of experimental results. However, the effects from DBP might be separable from those due to ligands formed from the "Ultrasene." If so, a quantitative study of unwashed solvent would avoid the complications induced by washing while still throwing some light on diluent degradation.

This simpler situation was found to be susceptible to a quantitative approach, at least for degradation at $40^{\circ} \mathrm{C}$. Both the gross effect of all degradation products together and the effect of DBP alone on zirconium extraction coefficients with $3 M$ nitric acid are approximately linear with concentration. This relationship infers that the over-all extraction coefficlent for zirconium is the sum of three terms. The first term, due to TBP, will be constant so long as TBP is constant. The second term is due to DBP. Once the total extraction coefficient is corrected for TBP and DBP, the remainder is proportional to the concentration of ligands formed from the diluent. Such proportional relationship permits the determination of the concentration of ligands on a relative basis. With the relative concentration of ligands being known, the kinetics of formation of the ligands may be examined.

The use of this technique shows that at $40^{\circ} \mathrm{C}$ :

1. With nitric acid present, but no nitrous acid present, DBP and TBP account for all of the zirconium affinity of degraded solvent. Degradation of the diluent makes no contribution.

2. Even with nitrous acid present the diluent makes no contribution until the nitric acid concentration in the organic phase is greater than $0.44 \mathrm{~m} / 1$.

3. In the region where ligands from the diluent may be measured, their rate of formation depends on concentration of nitrous acid to the one-half power and on total acid concentration to the fourth power.

At $70^{\circ} \mathrm{C}$ the degradation of solvent becomes complicated even when the solvent is not washed after degradation. At this temperature if no nitrous acid is included, it is generated after a few days, presumably by interactions of nitric acid with the solvent. The increase in concentration of nitrous acid is accompanied by a decrease in concentration of nitric acid. The uncontrollable change in these variables prevents quantitative investigation. However, 
qualitatively. the picture is the same - that is, DBP accounts for zirconium complexing of degraded solvent except at high concentrations of nitric acid with itrous acid present. These conclusions are based on the following experiments:

\section{Experimental Work}

The first experiment showed that the extraction coefficient for zirconium is nearly a linear function of the concentration of ligands (including DBP) formed in degraded solvent, provided the solvent is not washed with caustic after degradation. The change in distribution of zirconium is then a basis for following the relative rates of formation of such ligands since the amount of ligands formed is directly proportional to the extraction coefficient.

The solvent was degraded at $40^{\circ} \mathrm{C}$ for five days while containing $0.6 \mathrm{M}$ $\mathrm{HNO}_{3}$ and $0.02 \mathrm{M} \mathrm{HNO}$. The degraded solvent was then diluted with various amounts of virgin solvent. The dilutions of the degraded solvent were equilibrated with $3 \mathrm{M} \mathrm{HNO}_{3}$ and then equilibrated with tracer zirconium in 3M nitric acid for twenty hours at $23^{\circ} \mathrm{C}$.

Ligand Concentration vs.

Extraction Coefficient for Zirconium

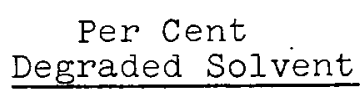

100

50

25

$12-1 / 2$
Extraction Coefficient for Zirconium*

1.19

0.56

0.27

*Extraction due to TBP subtracted

The second experiment was concerned with the effect of the addition of DBP to 30\% TBP - "Ultrasene," on the extraction coefficients of zirconium between $3 \mathrm{M} \mathrm{HNO}_{3}$ and solvent at $23^{\circ} \mathrm{C}$. The effect is almost linear. The linear effect permits an easy correction for the contribution of the DBP to the total degradation effect in subsequent studies.

The results, given in the table below, demonstrate that as little as 0.001 volume per cent of DBP in 30\% TBP - "Ultrasene" makes a measurable contribution to the over-all zirconium extraction coefficient and that the extraction coefficient increases markedly with increasing concentrations of DBP. The data have been corrected for extraction due to TBP by subtracting 0.27 from the measured extraction coefficient. The value, 0.27 , was obtained as the extraction due to TBP alone. The plot of the log of the per cent DBP versus the log of that portion of the extraction coefficient due to DBP alone gave a straight line for all except the two highest concentrations. The slope of this line was 1.25 .

Effect of DBP on Extraction Coefficient for Zirconium

\begin{tabular}{lccc}
$\begin{array}{l}\text { Volume } \\
\% \text { DBP }\end{array}$ & $\begin{array}{c}\text { Extraction Coefficient } \\
\text { for Zirconium }\end{array}$ & \multicolumn{2}{c}{$\begin{array}{c}\text { Extraction Coefficient } \\
\text { Corrected for Extraction } \\
\text { by TBP }\end{array}$} \\
\cline { 2 - 3 } 0 & 0.268 & - \\
0.001 & 0.316 & 0.048 \\
0.01 & 1.04 & 0.77 \\
0.05 & 5.9 & 5.6 \\
0.10 & 15.0 & 14.8 \\
0.50 & 35.1 & 35.5 \\
1.00 & 60 & 12 & 01260
\end{tabular}


In the next experiment, the rate of degradation of $30 \%$ TBP - "Ultrasene" was studied at $40^{\circ} \mathrm{C}$ at three different acid concentrations. No nitrous acid was present except for small amounts that might have formed as the solvent degraded. The rates were followed by measuring the distribution coefficients of zirconium at $23^{\circ} \mathrm{C}$ between $3 \mathrm{M} \mathrm{HNO}_{3}$ and samples of solvent which had been degraded for varying lengths of time in the absence of an aqueous phase and which had not been washed with $\mathrm{NaOH}$ prior to these measurements. The degradation process was followed in solvent samples which were $0.18 \mathrm{M}, 0.50 \mathrm{M}$, and $0.96 \mathrm{M}$ in $\mathrm{HNO}_{3}$.

The results shown in Table III, followed by the comparison which is given below, demonstrate that all of the degradation observed under these conditions is due to DBP formation. The rates of DBP formation calculated from the zirconium extraction coefficients in these experiments, and the effect of DBP on these coefficients are very close to the values obtained by E. K. Dukes (1). Dukes used another method for measuring DBP formation that depends on the effect of DBP on the distribution of tracer U-233.

The following table gives a comparison of the results obtained in this experiment with the rate of formation of DBP obtained by Dukes in the system $30 \%$ TBP-n-dodecane at various acid concentrations. The average rate per day over the nine-day period is used in this comparison.

\section{Comparison of Rates of DBP Formation} with those of $E$. K. Dukes

$\begin{array}{ccc}\begin{array}{c}\mathrm{HNO}_{3} \\ \text { moles/1ter, } \\ \text { Organic Phase }\end{array} & \begin{array}{c}\text { Volume \% DBP/Day } \\ \text { (This Experiment)* }\end{array} & \begin{array}{c}\text { Volume \% DBP/Day } \\ \text { (E. K. Dukes) }\end{array} \\ 0.066 & 0.00082 & 0.00072 \\ 0.18 & & 0.00091 \\ 0.22 & & 0.0016 \\ 0.45 & 0.0013 & \\ 0.50 & & 0.0014 \\ 0.64 & & 0.0016 \\ 0.82 & 0.0013 & \\ 0.96 & & \end{array}$

*Calculated assuming extraction of $\mathrm{Zr}$ is due only to TBP + DBP

In the fourth experiment the rate of degradation of $30 \%$ TBP - "Ultrasene" was studied at $40^{\circ} \mathrm{C}$ in a series of solvent samples in which the nitric and nitrous acid concentrations were varied over a wide range. The degradation process was followed by measurement of the change of the extraction coefficient of zirconium between $3 \mathrm{M}^{\mathrm{H}} \mathrm{HNO}_{3}$ and unwashed, degraded solvent as described in the preceding section.

The results (Table IV) demonstrated that at low nitric acid concentrations in the organic phase (up to $0.44 \mathrm{M}$ ) DBP formation is almost entirely responsible for the observed increase in the zirconium extraction coefficients even in fairly high concentrations of nitrous acid. At higher nitric acid concentrations, $0.64 \mathrm{M}$ and greater in the organic phase, DBP formation is only partly responsible for zirconium extraction. The formation of the zirconium complexing material other than DBP appears to be very sensitive to nitric acid concentration and to depend on the nitrous acid concentration but to a lesser extent.

Table IV is divided into two sections corresponding to two series of experiments. In the first series (A) the nitrous acid concentration was held constant and the nitric acid concentration was varied, while in the second series

\section{3


(B) the reverse was true. In the second series the nitric acid was maintained at a sufficiently high concentration so that the formation of degradation products

other than DBP could be measured. In this way the dependence of the rate of degradation on both nitric and nitrous acids can be established.

It can be seen from column three in Table IV that the contribution to zirconium extraction due to material other than DBP and TBP is negative but almost constant for the first few days in the case of the lowest acid concentrations, and then becomes more negative. A similar apparent anomaly holds for the data at $0.44 \mathrm{M}$ acid. The negative values must, however, be due to small inaccuracies in the determination of the original rate of $\mathrm{DBP}$ formation. It will be noted that the values obtained are quite small. It can be concluded therefore that the only material contribution to zirconium extraction in these two cases is DBP and TBP.

For solvent samples degraded at higher acid concentration the values given in column 3 show a general increase with increasing time. This may be interpreted as meaning that some other zirconium-complexing material has been formed.

Table $V$ shows the rate of increase of the zirconium distribution coefficient per day due to a ligand other than DBP. The first section (A) shows this quantity as a function of nitric acid concentration at constant nitrous acid concentration, while the second section (B) shows it as a function of nitrous acid concentration at constant nitric acid content. The nitric acid concentration in Table V (A) was calculated by subtracting the nitrous acid concentration from the total acidity as determined by titration of the solvent with $\mathrm{NaOH}$ to a phenolphthalein end point. In neither was the nitric acid or the nitrous acid concentration maintained exactly constant but the deviations are believed to be sufficiently small so that the dependence on the individual variables is valid.

If the rate of reaction may be represented by the following equation

$$
\frac{d\left(E-E_{T B P}-E_{D B P}\right)}{d t}=k\left(\mathrm{HNO}_{3}\right)^{m}\left(\mathrm{HNO}_{2}\right)^{n}
$$

a plot of the log of the rate versus the $\log$ of the nitric acid concentration at constant nitrous acid concentration should give a straight line of slope $\mathrm{m}$. A plot of the $\log$ of the rate versus the $\log$ of the nitrous acid concentration at constant nitric acid concentration should give one of slope $n$.

When the data in Table $V$ were treated in this manner a value of 3.7 was obtained for $\mathrm{m}$ and 0.47 for $\mathrm{n}$. Although these results are subject to considerable uncertainty, they demonstrate that the rate of formation of zirconium-complexing ligands other than DBP are dependent on both the nitric and nitrous acid concentrations in the organic phase and that the rate of reaction is much more sensitive to the former than to the latter.

In the fifth experiment the rate of generation of nitrous acid in the solvent phase and the degradation of 30\% TBP - "Ultrasene" were studied in systems containing nitric acid both in the presence and in the absence of added nitrous acid. The process was studied at two different acid concentrations (0.175M and $0.93 \mathrm{M}$ in the organic phase) in the absence of added nitrous acid but at only one concentration $(0.95 \mathrm{M})$ in its presence. It was followed by measurement of total acidity, nitrous acid concentration and the distribution coefficient of zirconium for solvent samples which had remained at $70^{\circ} \mathrm{C}$ for varying lengths of time. The results are tabulated in Tables VI and VII.

In contrast to the results obtained at $40^{\circ} \mathrm{C}$, nitrous acid was generated during solvent degradation at $70^{\circ} \mathrm{C}$. Its rate of formation in the absence of added nitrous acid was found to be considerably larger at the higher nitric acid concenration than at the lower one and the general shape of the curve of nitrous acid s. time is suggestive of an autocatalytic process. This type of process is also

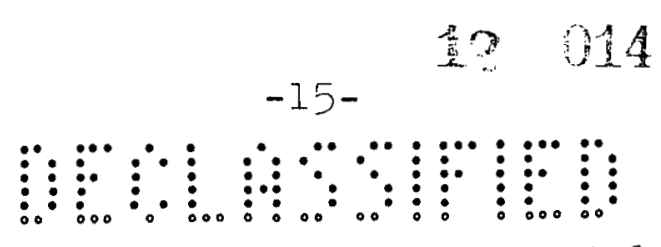


consistent with the increased rates found when nitrous acid was present initially.

When nitrous acid was formed in fairly large amounts its formation was accompanied by the loss of nitric acid. In both cases where the nitric acid concentration was initially about $0.9 \mathrm{M}$ it appeared to level of $\mathrm{f}^{\prime}$ at about $0.55 \mathrm{M}$ while the nitrous acid increased to a final concentration of $0.05 \mathrm{M}$. This result indicated that both these components were approaching an equilibrium value.

At $70^{\circ} \mathrm{C}$ as at $40^{\circ} \mathrm{C}$, DBP formation was responsible for most of the zirconium extraction in solvent which was not washed after degradation. A comparison of the observed zirconium distribution coefficients with those which were calculated as due to TBP and DBP shows good agreement. (columns 4 and 5 in Tables VI and VII).

\section{EXPERIMENTAL METHODS}

Experimental techniques used in the five experiments above are described in the following discussion:

\section{Effect of DBP on the Extraction Coefficient of Zirconium}

A sample of virgin 30\% TBP - "Ultrasene" was washed with $1 \mathrm{M} \mathrm{NaOH}$ and then with water. The organic phase was separated from the aqueous phase by centrifugation. Measured volumes of pure DBP were added to aliquots of the solvent to obtain the higher concentration while the lower ones were prepared by dilution of aliquots of the former in virgin 30\% TBP - "Ultrasene."

Zirconium extraction coefficients were measured by the technique described in a subsequent section.

\section{Solvent Degradation}

All of the degradation studies described in this section were carried out in the following manner:

Samples of 30\% TBP - "Ultrasene" were washed with IM NaOH and then water. Each sample was then equilibrated with nitric acid to give approximately the desired concentration in the organic phase. An aliquot of $5 \mathrm{M} \mathrm{NaNO}_{2}$ was then added to the organic phase after the acid had been removed and the mixture agitated. In this manner the desired $\mathrm{HNO}_{2}$ concentration was obtained with a minimum of gas evolution. In those cases where a constant nitric acid concentration was desired the organic phase was re-equilibrated with nitric acid of the desired concentration and the aqueous phase again was removed by centrifugation.

After the proper concentrations of nitric and nitrous acids were obtained the solvent was divided into several $10-\mathrm{ml}$ portions and each of these was placed in a 15-ml glass vial with a screw cap containing a polythene liner. A stream of nitrogen was blown over the surface of the solvent in each vial for one minute before the vials were capped. The vials were then placed in a constant temperature water bath at 40 or $70^{\circ} \mathrm{C}$.

Vials were removed from the bath at intervals and a portion of the contents of each was titrated for total acid and concentration of $\mathrm{HNO}_{2}$. The remainder of each sample was washed with an equal volume of water and then preequilibrated with an equal volume of $3 \mathrm{M}$ nitric acid. Zirconium extraction coefficients were then determined.

\section{Determination of Zirconium Extraction Coefficients}

Four ml of solvent which had been pre-equilibrated with 3M $\mathrm{HNO}_{3}$ was placed in a "dri-filmed" 40-ml glass vial. Four ml of zirconium tracer in $3 \mathrm{M}$ nitric acid was added and the vial was closed with a polythene screw cap. The vial was then placed on a wrist action shaker and agitated for 20 hours.

$-16-$

$$
\because 305
$$

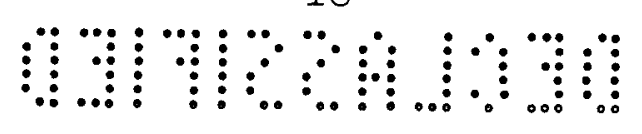


At the end of this period allquats of both phases. were mounted on stainless steel plates and counted for zirconium beta activity by differential beta counting on a PCC-10 gas flow counter.

\section{Determination of Nitric Acid and Nitrous Acid}

Total acid in the organic phases was determined by adding an aliquot of solvent to about $50 \mathrm{ml}$ of water and titrating to a phenolphthalein end point.

Nitrous acid was determined by adiing an allquot of solvent to an aqueous solution containing a known volume of standard ceric ammonium sulfate solution and back titrating with a standara solution of ferrous ion. Ferroin was used as an indicator.
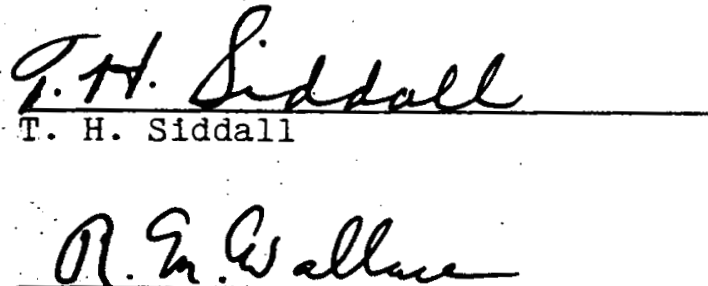

R.M. Wallace

Separations Chemistry Division

\section{BIBLIOGRAPHY}

1. Dukes, E. K. The Formation and Effects of Dibutyl Phosphate in Solvent

Extraction. E. I. du Pont de Nemours \& Co., DP-250, November 1957. 


\section{TABLE I}

EFFECT OF. DURATION OF CAUSTIC WASHES, $30-$ SECOND ACID WASH

\begin{tabular}{l} 
Duration of \\
Caustic Wash \\
\hline 0 minute \\
1 minute \\
5 minutes \\
30 minutes \\
1 hour \\
4 hours \\
16 hours
\end{tabular}

" $Z$ " Number After Washing With

- $1 \mathrm{M} \cdot \mathrm{NaOH} \quad 4 \mathrm{M} \mathrm{NaOH}$

690 : 690

$500 \quad-$

$550 \quad 560$

$600 \quad 610$

$640 \quad 630$

$720: 760$

- 880

TABLE II

EFFECT OF DURATION OF ACID WASH, I 6 -HOUR CAUSTIC WASH

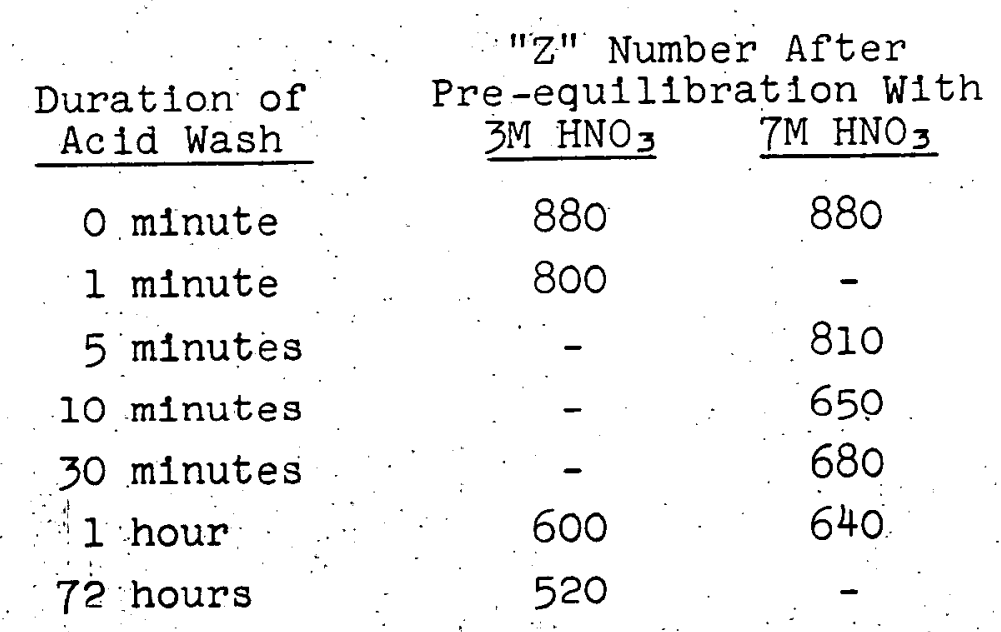

12017

$-18-$ 


\section{DEGRADATION OF 30\% TBP - "ULTRASENE" IN}

ABSENCE OF NITRITE AT $40^{\circ} \mathrm{C}$

\begin{tabular}{|c|c|c|c|c|}
\hline $\begin{array}{l}\text { Time, } \\
\text { days }\end{array}$ & $\begin{array}{c}\text { Total } \\
\text { Extraction } \\
\text { Coefficient } \\
\text { for } \\
\text { Zirconium } \\
\end{array}$ & $\begin{array}{l}\text { Extraction } \\
\text { Coefficient } \\
\text { for Zirconium } \\
\text { Corrected for } \\
\text { Extraction } \\
\text { by TBP } \\
\end{array}$ & $\begin{array}{l}\text { Volume } \\
\text { of DBP }\end{array}$ & $\begin{array}{l}\text { Volume } \\
\text { \% DBP/Day }\end{array}$ \\
\hline \multicolumn{5}{|c|}{$0.18 \mathrm{M} \mathrm{HNO}_{3}$ in the organic phase } \\
\hline 1 & 0.309 & 0.129 & 0.0023 & 0.0023 \\
\hline 3 & 0.355 & 0.175 & 0.0031 & 0.0010 \\
\hline 7 & 0.55 & 0.374 & 0.0057 & 0.0009 \\
\hline 9 & 0.84 & 0.66 & 0.0090 & 0.0010 \\
\hline \multicolumn{5}{|c|}{$0.50 \mathrm{M} \mathrm{HNO}_{3}$ in the organic phase } \\
\hline 1 & 0.361 & 0.181 & 0.0032 & 0.0032 \\
\hline 3 & 0.51 & 0.333 & 0.0052 & 0.0017 \\
\hline 7 & 1.11 & 0.93 & 0.0112 & 0.0016 \\
\hline 9 & 1.50 & 1.32 & 0.0149 & 0.0016 \\
\hline \multicolumn{5}{|c|}{$0.96 \mathrm{M} \mathrm{HNO}_{3}$ in the organic phase } \\
\hline 1 & 0.337 & 0.157 & 0.0029 & 0.0029 \\
\hline 3 & 0.51 & 0.329 & 0.0051 & 0.0017 \\
\hline 7 & 0.97 & 0.79 & 0.0101 & 0.0014 \\
\hline 9 & 1.51 & 1.33 & 0.0150 & 0.0017 \\
\hline
\end{tabular}

$-19-\quad 1908$

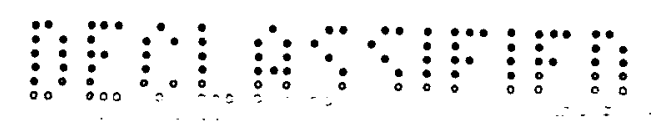




\section{TABLE IV (A)}

SOLVENT DEGRADATION AT $40^{\circ} \mathrm{C}$ IN PRESENCE

OF $\mathrm{HNO}_{2}$ AND $\mathrm{HNO}_{3} ;$ CONSTANT $\mathrm{HNO}_{2}$, VARYING $\mathrm{HNO}_{3}$

( I)

Time,

days

1

2

3
7
3

13

1

2

\begin{tabular}{l}
3 \\
7 \\
\hline
\end{tabular}

13

1

2

3

5

9

1.1

1

2

3

4

5
7

9
(2)

Extraction Coefficient for Zirconium

$0.13 \mathrm{M} \mathrm{H}^{+} 0.044 \mathrm{M} \mathrm{HNO}_{2}$

$$
\begin{aligned}
& 0.197 \\
& 0.225 \\
& 0.257 \\
& 0.365 \\
& 0.459
\end{aligned}
$$

$0.44 \mathrm{M} \mathrm{H}^{+} 0.044 \mathrm{M} \mathrm{HNO}_{2}$

0.297

0.441

0.54

0.87

1.48

$0.65 \mathrm{M} \mathrm{H}^{+} 0.037 \mathrm{M} \mathrm{HNO}_{2}$

0.422

0.71

0.84

1.15

1.55

2.00

2. 21

2.93

$0.75 \mathrm{M} \mathrm{H}^{+} 0.033 \mathrm{M} \mathrm{HNO}_{2}$

0.461

0.82

1.12

1.31

2.03

2. 37

2.51

3.21
(3)

Extraction Coefficient Due to Ligands
0.040

0.096

0.085

$-0.093$

$-0.30$

0.172

0.36

0.40

0.58

0.86

1.04

0.98

1.35

0.211

0.47

0.68

0.74

1.34

1.41

2.22

1.63 
SOLVENT DEGRADATION AT $40^{\circ} \mathrm{C}$ IN PRESENCE

$\underline{O F} \mathrm{HNO}_{2}$ AND $\mathrm{HNO}_{3} ;$ CONSTANT $\mathrm{HNO}_{3}$, VARYING $\mathrm{HNO}_{2}$

(1)

Time,

days

1
3
6
8

10

1
3
6
8

10

1
3
6
8
10

1
3
6
8
10
(2)

Extraction Coefficient for Zirconium

$0.86 \mathrm{M} \mathrm{H}^{+} 0.010 \mathrm{M} \mathrm{HNO}_{2}$

0.477

0.99

2.13

2.97

3.47

$0.87 \mathrm{M} \mathrm{H}^{+} 0.022 \mathrm{M} \mathrm{HNO}_{2}$

$$
\begin{aligned}
& 0.54 \\
& 0.94 \\
& 2.65 \\
& 3.04 \\
& 4.18
\end{aligned}
$$

$0.853 \mathrm{M} \mathrm{H}^{+} 0.036 \mathrm{M} \mathrm{HNO}_{2}$

0.60

1.25

3.24

3.90

4.36

$0.863 \mathrm{M} \mathrm{H}^{+} 0.049 \mathrm{M} \mathrm{HNO}_{2}$

0.62

1.32

2.97

4.56

6.01

\section{(3)}

Extraction Coefficient Due to Ligands

0.127

0.54

1.31

1.87

2.07

0.291

0.49

1.83

1.94

2.78
0.347
0.80
2.42
2.80
2.96

0.372

0.87

2.15

3.46

4.58

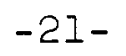

\section{ए।}


TABLE V

SUMMARY OF DEGRADATION RESULTS

(A) Rates of Degradation at Constant $\mathrm{HNO}_{2}(0.035 \mathrm{M})$

$\begin{array}{cc}\mathrm{HNO}_{3} \text { Concentration } & \frac{\frac{d\left(E-E_{D B P}\right) * \text { per day }}{d t}}{0.61 \mathrm{M}} \\ 0.72 \mathrm{M} & 0.12 \\ 0.82 \mathrm{M} & 0.25 \\ 0.34\end{array}$

Slope of a plot of $\log \frac{d(E-E D B P}{d t}$ vs. $\log \left(\mathrm{HNO}_{3}\right)$ is 3.7 .

(B) Rate of Degradation at Constant $\mathrm{HNO}_{3}$ (0.85M)

\begin{tabular}{|c|c|}
\hline $\mathrm{HNO}_{2}$ Concentration & $\frac{d(E-E D B P}{d t}$ per day \\
\hline 0.010 & 0.22 \\
\hline 0.022 & 0.27 \\
\hline 0.036 & 0.34 \\
\hline 0.049 & 0.44 \\
\hline
\end{tabular}

Slope of a plot of $\log \frac{d(E-E D B P}{d t}$ vs. $\log \left(\mathrm{HNO}_{2}\right)$ is 0.47 .

* Extraction coefficient for zirconium corrected for extraction by DBP.

$-22-\quad 921$ 


\section{DEGRADATION OF $30 \%$ TBP - "ULTRASENE" AT $70^{\circ} \mathrm{C}$}

NO ADDED $\mathrm{HNO}_{2}$

(I)

(2)

(3)

Time,

days

0

1

4

5

5

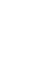

(4)

Measured Extraction Coefficient for Zirconium

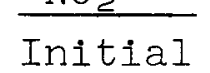

$\mathrm{HNO}_{3}$ in Organic Phase
(5)

Calculated Extraction Coefficient for Zirconium

Initial $\mathrm{HNO}_{3}$ in Organic Phase 0.929M

00.83 None 0.25

$10.93 \quad$ None 3.62

$\begin{array}{llll}4 & - & 0.018 \mathrm{M} & 48.8\end{array}$

$\begin{array}{llll}5 & 0.56 & 0.044 & 36.1\end{array}$

6.3

32.3

40.3 
CONFIDENTIAL

TABLE VII

DEGRADATION OF 30\% TBP - "ULTRASENE" AT $70^{\circ} \mathrm{C}$ WITH ADDED $\mathrm{HNO}_{2}$

(1)

(2)

(3)

(4)

(5)

Time, hours $\mathrm{H}^{+} \quad \mathrm{NO}_{2}^{-}$

$\begin{array}{lll}0 & 0.95 & 0.0265\end{array}$

$\begin{array}{lll}1 & 0.92 \quad 0.0260\end{array}$

$2 \quad 0.90 \quad 0.0346$

$\begin{array}{lll}3 & 0.88 & 0.0378\end{array}$

$\begin{array}{lll}4 & 0.87 & 0.0463\end{array}$

$\begin{array}{lll}6 & 0.82 & 0.0350\end{array}$

$\begin{array}{lll}7 & 0.79 & 0.0340\end{array}$

47
0.55
0.051

Measured

Extraction Coefficient for Zirconium

0.27

0.74

1.02

1.60

1.29

2.83

2.64

18.0
Calculated Extraction Coefficient for Zirconium

0.27

0.64

0.74

0.97

1.20

1.62

1.87

15.5

\section{3}

